\title{
O Sistema Flexível de Turismo: avanço na análise sistêmica do Turismo
}

\author{
The Flexible Tourism System: advance in the systemic analysis of \\ Tourism
}

\section{El Sistema Flexible de Turismo: avance en el análisis sistémico del Turismo}

\author{
Guilherme Garcia Velasquez \\ Professor Adjunto da Universidade Federal de Mato Grosso do Sul-UFMS \\ Doutor em Turismo e Hotelaria pela Universidade do Vale do Itajaí-UNIVALI \\ guigave@hotmail.com
}

Josildete Pereira de Oliveira

Coordenadora, Docente e Pesquisadora do Programa de Pós-Graduação Stricto Sensu- Doutorado e Mestrado Acadêmico em Turismo e Hotelaria da Universidade do Vale do Itajaí-UNIVALI

Doutora em Geografia pela Université de Caen Basse Normandie- França

joliveira@univali.br

Data de submissão: 21/02/2018 - Data de aceite: 19/03/2018

\begin{abstract}
Resumo: Considerando a dinamicidade e a complexidade da atividade turística, o presente estudo considera a Teoria Geral dos Sistemas como ideal para analisar a área. Isso pelo fato dela propiciar uma análise holística e complexa do turismo. Assim, o objetivo principal deste trabalho é apresentar um modelo de análise sistêmica capaz de analisar uma realidade turística e que considere as especificidades do turismo na pós-modernidade. Para tanto, foram analisadas propostas de análise sistêmica do turismo a partir da década de 60, confrontando-as às peculiaridades do turismo na "atualidade", o que gerou a criação de um modelo sistêmico atualizado. Trata-se de um estudo qualitativo e bibliográfico com etapa empírica realizada no destino de Bonito-MS, com o intuito de validar o modelo criado (pauta de outro trabalho científico). Percebeu-se que a atividade turística resulta de um processo de transformação inerente à passagem dos séculos XX-XXI, caracterizada pela inserção da tecnologia no desenvolvimento das atividades, nas mudanças nas formas de comunicação, no apelo às questões da qualidade e ambientais. Assim, criou-se o denominado Sistema Flexível de Turismo, cuja maior característica foi a existência de elementos volantes, capazes de se moverem entre os subsistemas componentes do sistema, de acordo com a vocação da realidade estudada. Palavras-Chave: Teoria Geral dos Sistemas; Método; Sistema Flexível de Turismo.
\end{abstract}

Abstract: In view of the dynamics and complexity of tourism, this study considers General Systems Theory as the ideal method for analyzing this subject. This is because it enables a holistic and complex analysis of tourism. Thus, the main purpose of this work was to present a systemic analysis model capable of analyzing a tourism reality, and that considers postmodern tourism specifications. Therefore, tourism systemic analysis proposals were analyzed from the 1960s onwards, comparing them with the characteristics of present-day tourism, which led to the creation of an updated systemic model for tourism analysis. This is a qualitative 
and bibliographic study with an empirical stage, performed in the tourism destination of Bonito, Mato Grosso do Sul, in order to validate the model created (the main theme of another scientific article). It was noted that tourism activity is the result of a process of transformation inherent to the transition from the $20^{\text {th }}$ to the $21^{\text {st }}$ Centuries; characterized by the use of new technology in the development of activities, changes in forms of communication; and the focus on quality and environmental issues. Hence, the Flexible Tourism System was created, the main feature of which was the existence of "floating" elements, capable of moving between the component subsystems of the system, depending on the vocation of the reality studied. Keywords: General System Theory; Method; Flexible Tourism System.

Resumen: Considerando la dinamicidad y la complejidad de la actividad turística, el presente estudio considera la Teoría General de los Sistemas como ideal para analizar el área. Eso por el hecho de ella proporcionar un análisis holístico y complejo del turismo. Así, el objetivo principal de este trabajo es presentar un modelo de análisis sistémico capaz de analizar una realidad turística que considere las especificidades del turismo en la posmodernidad. Para tanto, fueron analizadas propuestas de análisis sistémico del turismo a partir de la década del 60, confrontando a las peculiaridades del turismo en la "actualidad", lo que genero la creación de un modelo sistémico actualizado. Se trata de un estudio cualitativo y bibliográfico con etapa empírica realizada en el destino de Bonito-MS, con el objetivo de validar el modelo creado (lista de otro trabajo científico). Se percibió que la actividad turística resulta de un proceso de transformación inherente al paso de los siglos XX-XXI, caracterizada por la inserción de la tecnología en el desarrollo de las actividades, en los cambios en las formas de comunicación, en el llamamiento a las cuestiones de la calidad y las ambientales. De esta forma, se creó el denominado Sistema Flexible de Turismo, cuya mayor característica fue la existencia de elementos volantes, capaces de moverse entre los subsistemas componentes del sistema, de acuerdo con la vocación de la realidad estudiada. Palabras clave: Teoría General de los Sistemas; Método; Sistema Flexible de Turismo.

\section{Introdução}

Muitas são as razões que levam as pessoas a se dirigirem aos variados locais para efeitos de prática turística. Se de um lado a peculiaridade de uma determinada região gera interesse a um dado público; de outro, as condições econômicas favoráveis da outra localidade também podem ser o fator de emissão de turistas.

Independentemente da razão, o fato é que inúmeras pessoas se deslocam de seu local habitual de residência, por vários motivos, em busca de desenvolverem a atividade turística, algo, inclusive, fortemente debatido historicamente.

Nessa perspectiva de movimentação e deslocamento é que surgem as discussões sistêmicas de forma geral. É o deslocamento espacial-geográfico, uma das principais condições sistêmicas que caracteriza a discussão iniciada, que sempre conta com um ponto de origem e outro de destino, uma zona de partida e outra de interesse, algo trabalhado por Leiper (1979).

Assim, não é incorreto afirmar que tratar de sistemas é estar aberto a mergulhar em uma dimensão quase virtual, repleta de uniões, de conexões e de sobreposições. Por essa razão é que existem diversas maneiras de se apresentar os modelos sistêmicos (GETZ, 1985); (CHRISTOFOLETTI, 1977; 1999).

Para Bertalanffy (1975), seu criador, a Teoria dos Sistemas representa uma ciência geral que lida com totalidades, ou seja, ela difere da rigidez cartesiana imposta à ciência, que propõe uma análise aprofundada de partes fragmentadas. O sistemismo propõe que o todo representa mais que a soma das partes. Assim, a referida teoria incentiva análises totalitárias, como maneira de melhor compreender realidades. É nesse sentido que se considera pertinente a utilização da Teoria Geral dos Sistemas para analisar realidades turísticas.

Resultante das contribuições de todos aqueles estudos sistêmicos da atividade turística desenvolvidos até o final do século XX (CUERVO, 1967); (LEIPER, 1979); (SESSA, 1985); (BOULLÓN; 1985); (GETZ, 1986); (ACERENZA, 1986;1994) e (BENI, 1988; 1997), o presente estudo avança, a partir do que se compreende como "turismo na atualidade" (TRIGO, 1998); (MOLINA, 2004); (YOMAN, BRASS \& McMAHON-BEATTIE, 2007); (CACHO \& AZEVEDO, 2010), nas propostas de análises sistêmicas desenvolvidas pelos grandes 
estudiosos, apresentando, como resultado, um modelo de análise atualizado, capaz de compreender as distintas realidades turísticas. Trata-se de seu principal objetivo.

Assim, o Sistema Flexível de Turismo, como denominado, propicia a compreensão da complexidade e da dinâmica da atividade turística, a partir da interconexão de elementos, forças ambientais, da mesma maneira que salienta a necessidade de transformação de determinadas forças ambientais em elementos em ocasiões específicas.

Tem-se como máxima que a atividade turística, por sua condição compósita, formatada pela união de inúmeros serviços isolados e que somados geram a experiência turística, caracteriza-se por uma realidade bastante complexa e altamente dinâmica.

Não apenas a teia formada pela interconexão dos serviços é que lhe permite tal caracterização, mas ainda o próprio resultado das relações entre aqueles que se dirigem à dada localidade turística e que, inevitavelmente, interagem com a comunidade receptiva.

Assim, esse conjunto de serviços oferecidos/ prestados, somado ao câmbio de informações e trocas de carga cultural, confere à atividade um status de unicidade, que ao mesmo tempo gera encanto e preocupações intensas, dados os possíveis impactos que podem surgir a partir dessa relação (VERA REBOLLO, 1992), (WILLIANS, 1998), (MOWFORTH \& MUNT, 2003), (RUSCHMANN, 2003).

Ainda, sobre o sistema, há de ser mencionado que um dado destino turístico, assim como um estado ou país, pode ser considerado um sistema. Não obstante, um simples elemento de referido sistema poderá, dependendo da perspectiva de análise, transformar-se num sistema altamente complexo.

Nesse diapasão, conforme mencionado por Christofoletti $(1977,1999)$, muito importante se faz definir, com antecedência, qual instância, ou melhor, qual abrangência é que se pretende dar ao estudo sistêmico em andamento, justamente para que se tenha a definição clara de quais serão seus elementos, bem como quais serão os seus limites de fronteira.

No caso do presente artigo, sempre que for mencionada a nomenclatura Sistema Flexível de Turismo, buscar-se-á entendê-lo como um destino turístico isolado. Sabe-se que, ao considerar um destino turístico um sistema há, da mesma maneira que estabelecer qual será seu território de análise, já que muitas vezes o referido território ultrapassa a própria fronteira geográfica do município. No caso em questão, a proposta do Sistema Flexível de Turismo ora apresentada considera o destino turístico a partir dos limites geográficos fronteiriços a ele imposto.

Diante do exposto, evidencia-se que o trabalho em questão possui forte apelo metodológico, resultado de uma análise sobre a abordagem sistêmica em um contexto macro-generalista, apoiando-se em um segundo momento, especificamente, em obras que discutiram a análise do turismo a partir dessa ótica.

De caráter bibliográfico, o estudo gerou uma série de modelagens que culminou em uma modelagem totalitária e que é apresentada neste manuscrito.

Este estudo, especificamente, prezou por apresentar uma modelagem sistêmica desenvolvida dentro de um princípio capaz de demonstrar sua organicidade e flexibilidade. Não se trata de um estudo que desenvolve considerações em torno da aplicabilidade do produto gerado, mas sua apresentação e reflexões em torno da mesma. Sobre a aplicabilidade do Sistema Flexível de Turismo, merece a menção de que a mesma é retratada em outro trabalho científico.

\section{A necessidade do avanço nos estudos sistêmicos}

A decisão de um estudo de caráter metodológico surgiu da compreensão da necessidade de propostas que avançassem nas discussões sistêmicas voltadas à atividade turística.

Após análise das obras elencadas durante o estudo bibliográfico, em especial daqueles autores considerados os "principais" investigadores no assunto, buscou-se levantar possíveis lacunas em suas propostas, que já não mais permitiam analisar a atividade turística a partir de sua condição pósmoderna ou atual.

Diante do confronto das propostas analisadas e realidade do turismo é que se propôs um método de análise sistêmica para o turismo, que não apenas fosse considerado adequado para o momento em questão, mas que ao passo que teorizasse, também apresentasse sua modelagem. 
Uma das grandes dificuldades de compreender o sistemismo nas discussões do turismo é a ausência de apresentações que disponibilizem a teoria e a modelagem de forma conjunta.
Algumas considerações levantadas na análise das obras clássicas da abordagem sistêmica aplicada ao turismo apresentam como resultado:

Quadro 1: Reflexões sobre principais propostas de análise sistêmica para o turismo, período de 1960-2000.

\begin{tabular}{|c|c|}
\hline Autor/Ano & nsiderações sobre sua proposta \\
\hline \begin{tabular}{|l} 
Cuervo \\
$(1967)$
\end{tabular} & $\begin{array}{l}\text { Embora tenha apresentado os elementos componentes do sistema turístico, não } \\
\text { apresentou modelagem do sistema, suas interconexões, tampouco explicitou } \\
\text { os componentes que se caracterizam por entrada de energia ou matéria (input), } \\
\text { processamento e saída (output). O autor, ao tratar sobre o sistema turístico, dá especial } \\
\text { enfoque na questão da comunicação inerente ao sistema eà atividade, o que, tempos } \\
\text { mais tarde, com o processo de globalização e mundialização mencionado por Beni } \\
\text { (1988; 1997), personificou-se no que se conhece por tecnologia, ressaltando que não } \\
\text { se entende por tecnologia apenas o desenvolvimento tecnológico das máquinas, mas, } \\
\text { ainda, a busca pela melhoria na prestação de serviços, controles efetivos de fluxos, } \\
\text { etc. Não obstante, a tecnologia, aparentemente tão imprescindível ao turismo, não é } \\
\text { por ele mencionada como ambiente do sistema, tampouco como elemento. }\end{array}$ \\
\hline $\begin{array}{l}\text { Leiper } \\
(1979)\end{array}$ & $\begin{array}{l}\text { Apresenta um estudo sobre o cenário do turismo a partir de três abordagens } \\
\text { específicas, que são: Econômica, Técnica e Holística. Sobre a última, atribui sua } \\
\text { existência à própria condição multifacetada da atividade, sendo por isso necessária } \\
\text { a utilização da Teoria Geral dos Sistemas para compreender o turismo como um } \\
\text { fenômeno. São os principais elementos do sistema turístico de Leiper (1979): } \\
\text { Turista, Polo Emissivo, Polo Receptivo, Rota de Trânsito e Indústria do Turismo. } \\
\text { Assim como Cuervo (1967), Leiper ressalta o importante papel do indivíduo na } \\
\text { atividade turística, mas não desenvolve nenhum posicionamento acerca de uma } \\
\text { relação mais específica entre esse indivíduo e turismo. Embora atribua importância } \\
\text { ao elemento humano no processo de turismo, Leiper (1979) não o coloca como } \\
\text { elemento componente de seu sistema. Leiper (1979) menciona em sua discussão a } \\
\text { relevância da tecnologia e a necessidade da manutenção cultural, mas não insere a } \\
\text { tecnologia como um elemento componente do sistema, senão como um ambiente } \\
\text { que permeia o espaço entre o polo emissivo, trânsito e receptivo. Sobre a manutenção } \\
\text { cultural, também não indica, por exemplo, a necessidade da existência de nenhum } \\
\text { órgão específico para sua regulação e que possa ser considerado um elemento do } \\
\text { sistema. Apenas indica que o ambiente que serve de base para o processo de turismo } \\
\text { sofre influências políticas e de ordem social. }\end{array}$ \\
\hline $\begin{array}{l}\text { Sessa } \\
(1985)\end{array}$ & $\begin{array}{l}\text { Desenvolve uma proposta de caráter teórico-conceitual, não demonstrando } \\
\text { efetivamente uma aplicabilidade específica. A proposta sistêmica de seu estudo } \\
\text { busca relacionar a compreensão da complexidade do turismo com a possibilidade } \\
\text { de desenvolvimento regional, ou seja, assim como Cuervo (1967), Boullón (1985) } \\
\text { relaciona o sistemismo com o planejamento turístico. Seu estudo apresenta-se } \\
\text { como um avanço ao de Neil Leiper (1979), não obstante, não o mencione como } \\
\text { referência nos estudos sistêmicos. Trata-se de um estudo de caráter estritamente } \\
\text { teórico-conceitual, não demonstrando, especificamente, a aplicabilidade do modelo/ } \\
\text { sistema. Ao tratar de outros sistemas que se conectam com o Sistema Turístico e } \\
\text { que podem claramente ser entendidos como subsistemas do mesmo, uma vez lido } \\
\text { seu manuscrito, menciona os Subsistemas Políticos e Econômicos, reconhecidos } \\
\text { por superestruturas em outros estudos. Da mesma maneira, Sessa (1985) menciona } \\
\text { um Sistema Tecnológico, mas não explicita a maneira com que a tecnologia se } \\
\text { personifica. }\end{array}$ \\
\hline
\end{tabular}




\begin{tabular}{|c|c|}
\hline & $\begin{array}{l}\text { Discute o sistemismo no turismo como cenário para o planejamento turístico. } \\
\text { Sua proposta sistêmica é similar àquela proposta por Leiper (1979), embora os } \\
\text { elementos tenham recebido outras denominações. Seu estudo menciona o fato da } \\
\text { não existência de inúmeros sistemas, mas um único sistema multifacetado. Dessa } \\
\text { forma, empenha-se em tratar a discussão sistêmica dentro da perspectiva oferta- } \\
\text { demanda, considerando um contexto de caráter comercial. Não atribui importância } \\
\text { ao elemento indivíduo-turista na discussão sistêmica. Assim como Cuervo (1967) } \\
\text { Leiper (1979) e Sessa (1985), faz menção à relevância da tecnologia, mas sem } \\
\text { apresentar um foco que a faça ser considerada importante como um elemento } \\
\text { componente do sistema. Seu modelo sistêmico não traz muito detalhamento sobre } \\
\text { os elementos reguladores da atividade, tampouco apresenta claramente os elementos } \\
\text { ambientais que são apropriados pela atividade turística. }\end{array}$ \\
\hline $\begin{array}{l}\text { Getz } \\
(1986)\end{array}$ & $\begin{array}{l}\text { Apresenta uma discussão teórica sobre as tipologias de modelos sistêmicos existentes, } \\
\text { assim como Cuervo (1967). Sua proposta não foi a de dar ênfase na exemplificação } \\
\text { da sistematização de modelos sistêmicos no turismo, mas a de avançar a discussão } \\
\text { sistêmica no campo do turismo, demonstrando sua importante relação com as ações } \\
\text { de planejamento. Dado o trato teórico e generalista sobre sistemas, não se detectou } \\
\text { qualquer consideração relevante sobre especificidades do sistema turístico a partir } \\
\text { de sua perspectiva. }\end{array}$ \\
\hline $\begin{array}{l}\text { Acerenza } \\
(1994)\end{array}$ & $\begin{array}{l}\text { Não demonstrou a aplicabilidade de um modelo específico, assim como Cuervo } \\
\text { (1967), Boullón (1985) e Getz (1986). Como Boullón (1985), apresentou os elementos } \\
\text { componentes da atividade turística, embora sua argumentação tenha demonstrado } \\
\text { assumir um caráter característico da gestão/planejamento. Menciona o pensamento } \\
\text { de Cuervo (1967) e Leiper (1979) como ideais para a compreensão da sistemática de } \\
\text { funcionamento do sistema turístico. Embora de forma mais robusta, sua proposta, } \\
\text { assim como a Leiper (1979), baseia-se no espaço entre o ponto de origem, trânsito, } \\
\text { ponto de destino. Para ele, permeiam por seu sistema elementos de ordem físico, } \\
\text { econômica, social, cultural, política e tecnológica. Assim como Leiper (1979), atribui } \\
\text { importância ao indivíduo, embora não o considere um elemento pontual do sistema. } \\
\text { Da mesma maneira, ao mencionar os elementos que permeiam sua proposta sistêmica } \\
\text { [físico, econômica, social, cultural, política e tecnológica], não desenvolve nenhum } \\
\text { aprofundamento de discussão, ou seja, não personifica, por meio de elementos } \\
\text { individuais, por exemplo, instituiçóes que sejam capazes de representar cada um } \\
\text { desses elementos. A tecnologia, por exemplo, embora apresentada como elemento, é } \\
\text { percebida em toda sua discussão como uma força ambiental. }\end{array}$ \\
\hline $\begin{array}{l}\text { Beni } \\
(1988 ; 1997)\end{array}$ & $\begin{array}{l}\text { Talvez por ter sido o último a ser analisado e por ter sido o responsável pela última } \\
\text { proposta inovadora no turismo, seu estudo é caracterizado por sua robustez. Propôs } \\
\text { o SISTUR para a análise do fenômeno Turismo como um modelo referencial, já que } \\
\text { nenhum outro método foi capaz de abranger a sua totalidade. Essa mesma compreensão } \\
\text { foi compartilhada nos estudos de Leiper (1979), Boullón (1985) e Acerenza (1994). } \\
\text { Para Beni (1988; 1997), sua proposta sistêmica do Turismo compreende o Conjunto } \\
\text { das Relações Ambientais, representado pelo meio Ecológico, Social, Econômico e } \\
\text { Político; Subsistema Infraestrutura e Superestrutura; Subsistema Dinâmica do } \\
\text { SISTUR, caracterizado pelos elementos Mercado, Oferta, Produção, Demanda, } \\
\text { Consumo e Distribuição, todos eles responsáveis pelo processamento da energia } \\
\text { (input), produção e consumo, bem como distribuição. Embora considere o elemento } \\
\text { indivíduo, fazendo, inclusive, uma alusão ao seu papel, que tanto representa energia, } \\
\text { como elemento do sistema, sua modelagem sistêmica não o inclui como elemento } \\
\text { do sistema. Embora apresente o Meio Ambiente como ambiente do sistema, } \\
\text { percebe-se que, dada a vocação de algumas localidades, muito mais do que ambiente } \\
\text { do sistema, os componentes ambientais, muitas vezes, assumem, inclusive, papel } \\
\text { de elemento essencial do sistema, dada sua relevância. Menciona a tecnologia no } \\
\text { processo de distribuição, mas não a personifica como um elemento inerente ao } \\
\text { sistema, imprescindível para o desenvolvimento da atividade. }\end{array}$ \\
\hline
\end{tabular}

Fonte: Os autores (2016). 


\section{O sistema flexível de turismo}

No caso do Sistema Flexível de Turismo, o que se propõe para uma melhor compreensão didática é a condição de que a atividade turística se molda pela sobreposição de 04 (quatro) grandes camadas [subsistemas], somadas a um posto de "elemento volante", explicado, a posteriori, e ao relevante papel do turista. Tais camadas se estruturam, especificamente por: 1-Aspectos Ambientais Apropriados; 2-Infraestruturas e Superestruturas Básicas; 3-Infraestruturas e Superestruturas Turísticas; 4-Trade/Mercado Turístico; Elemento volante/flexível; Turista.

A sobreposição das camadas em questão, por meio da articulação e da interconexão de seus elementos, somadas à entrada do elemento turista [input], geram como resultado final a experiência de viagem [output], retroalimentando, na sequência, o sistema em questão.

Para uma melhor compreensão da proposta é que se apresenta (em uma perspectiva de totalidade) o modelo do Sistema Flexível de Turismo. Ressalta-se que os modelos fragmentados dos subsistemas não são apresentados neste trabalho, dado o limitado espaço de um artigo científico.

\section{Subsistema 1: aspectos ambientais apropriados}

Trata-se do principal subsistema do sistema turístico proposto, já que não existe organização da atividade turística sem que se considere o processo de apropriação do espaço geográfico, ou consumo do espaço, espaço esse que serve de base para o desenvolvimento da atividade (SANTOS,1996); (GOELDNER; RITCHIE \& Mc'INTOSH, 2002); (CRUZ, 2006); (BEJARANO MARTINEZ, 2009).

Por essa razão e por servir de "cenário" imprescindível para a formatação do sistema turístico é que os Aspectos Ambientais Apropriados são os primeiros apresentados, ao tratar do Sistema Flexível de Turismo.

No que diz respeito aos Aspectos Ambientais apropriados, tem-se que os mesmos correspondem a toda e qualquer condição ambiental apropriada pela atividade turística, ou seja, o Meio Ambiente, entendido por Butler (1991) como tudo aquilo que engloba os reinos físico, humano e natural ou por Pacheco Fiorillo (2003) como sendo a soma do conjunto dos elementos naturais, artificiais e culturais, capazes de propiciarem o equilibro da vida.

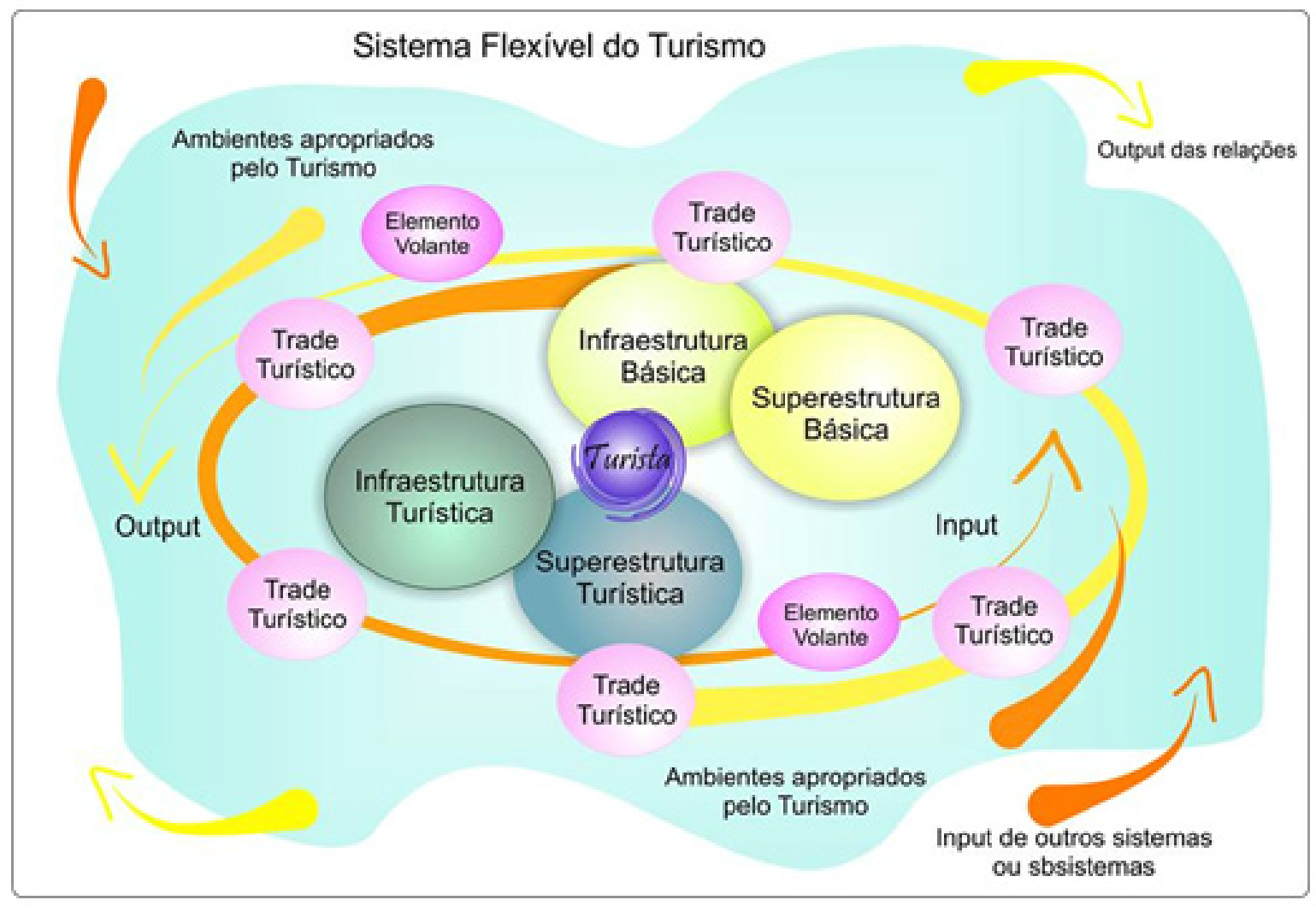

Figura 01: Sistema Flexível de Turismo - Modelo Plano Totalitário Fonte: Autores (2016), arte Thamyres Jacques 
Dessa forma, flora e fauna, características físico-geográficas, clima, valores identitários e culturais de comunidades, bem como aspectos econômicos e tecnológicos de uma dada localidade, representam condições ambientais geralmente apropriadas pela atividade turística.

O processo de apropriação de dada ou dadas característica(s) mencionada(s) é o responsável por gerar um determinado tipo de segmentação turística, o que, por consequência, delimita um perfil específico de visitante.

Inúmeros são os destinos nacionais e internacionais cujo apelo relaciona-se às questões de flora e fauna, a saber: Foz do Iguaçu-PR, Bonito-MS, Manaus-AM, Costa Rica, etc.

Outra característica ambiental que assume grande responsabilidade por direcionar as atividades turísticas é aquela definida por sua geografia física. Se dado território é caracterizado por uma cadeia de montanhas, rio, baía, falésia, istmo, lagoa ou planície, toda a organização da atividade deverá respeitar e se adaptar às condições impostas pela natureza, o que influenciará, sobremaneira, não apenas na forma de acesso ao atrativo em si, mas, ainda, na criação de infraestruturas básicas e turísticas, processo de urbanização, etc.

Os aspectos climáticos, supostamente, também definirão as formas de turismo pertinentes a determinadas localidades e, em especial, exigirão dos planejadores da atividade turística a criação de maneiras capazes de manter um fluxo turístico contínuo, mesmo em períodos de sazonalidade.

As questões patrimoniais materiais e imateriais, parte dos Aspectos Ambientais Apropriados do Sistema Flexível do Turismo, também possuem sua importância. Elas são responsáveis por gerarem nas sociedades grande curiosidade e o interesse de visitar os locais.

É a curiosidade pelas origens e pelos valores do outro que fazem com que inúmeras regiões se despontem como importantes zonas turísticas, graças à sua carga identitária.

Não menos importante, destaca-se a comunidade autóctone, aquela pertencente ao lugar turístico e que, muitas das vezes, tem relação direta ou indireta com a atividade, ou seja, é também apropriada pelo turismo. É ela a detentora da carga identitária e do conhecimento no que concerne às peculiaridades $\mathrm{da}$ região em questão. A relação turista versus autóctone é bastante relevante nos estudos do turismo e não apenas acontece no âmbito dos "aspectos ambientais apropriados” do Sistema Flexível de Turismo. A comunidade autóctone pertence, da mesma maneira, a todas as camadas do sistema, já que não existe atividade turística sem o elemento humano por "trás" das ações de gestão e articulação, da mesma forma que não existe atividade turística sem o elemento "turista".

Chamando atenção pelas riquezas ambientais, Vera Rebollo (1992), ao tratar da dimensão ambiental no processo de planejamento turístico, mencionou que a falta de planejamento é capaz de gerar inúmeros impactos de ordem negativa no ambiente, por meio de ações como: falta de controle de crescimento de áreas turísticas, com densidades superiores à capacidade de suporte das regiões; inadequação de uso do solo; escassa preservação de áreas livres; contaminação de águas; destruição e alteração de áreas com valor paisagístico; traçado inadequado de infraestruturas, etc.

Por essa razão, Dredge (1999:772), enfatiza que "um dos mais importantes desafios advindos dos objetivos da sustentabilidade é justamente o planejamento do destino".

Não bastassem os aspectos natural-geográficos e culturais, fazem também parte desse universo de aspectos ambientais as questões econômicas. Cientes de que a atividade turística se relaciona intimamente com a produção de capital, não existe maneira de dissociá-la dos aspectos econômicos. Estando a economia favorável, haverá a manutenção dos deslocamentos de turistas às inúmeras localidades existentes.

Inskeep (1991), entretanto, enfatiza que, na busca da maximização de benefícios econômicos nos destinos, deve-se pensar em constantes intervenções que busquem proteger o ambiente em que o turismo se sustenta, diminuindo, por consequência, os impactos sociais ou culturais. Tal menção explicita como todas as perspectivas ambientais também assumem uma condição de interdependência.

Atrelada às condições econômicas é que surge outro aspecto ambiental fundamental e fruto do desenvolvimento da própria sociedade, que é parte do Meio Ambiente. Trata-se da tecnologia.

Como mencionado outrora, não se deve entender a tecnologia e seu desenvolvimento 
dentro de uma perspectiva apenas computacional e informatizada (MOLINA, 2004). Ela é resultado de inúmeras modificações inerentes ao período de transição entre os séculos XX e XXI, da sociedade pós-moderna, pós-industrial ou Sociedade Técnico-Científico-Informacional (TRIGO, 1998); (MOLINA, 2004); (SANTOS, 2008); (CACHO \& AZEVEDO, 2010).

Graças às tecnologias é que o público turístico se tornou mais exigente, o que obrigou com que a prestação de serviços turísticos assumisse melhores patamares de atendimento. Nessa mesma hodierna, dado o processo de globalização e mundialização inerente a esse momento histórico (BENI, 1988; 1997), atribui-se grande valor às formas de comunicação e às ferramentas tecnológicas, que antes influenciavam o sistema e a atividade, mas que, agora, assumiram tamanha importância a ponto de passarem a ser consideradas imprescindíveis ao processo de produção do turismo, ou seja, o que se percebe é a ocorrência de um deslocamento espacial da força "tecnologia", da esfera ambiental para o cerne do sistema, em que a mesma se transforma num elemento imprescindível no processo de produção do mesmo.

Dada a complexidade inerente aos Aspectos Ambientais que são consumidos pela atividade turística, importante se faz explicitar que permeia sobre essa questão do processo de apropriação e consumo turístico a relevância do andamento de uma prática que seja minimamente organizada e que gere resultados os mais sustentados possíveis. Daí a impossibilidade de não atrelar a discussão sistêmica ao planejamento da atividade, algo já enfatizado por Cuervo (1967); Boullón (1985) e Acerenza (1994). O consumo predatório, embora exista, deixa de ser considerado, quando o intuito da discussão é o de refletir sobre um modelo sistêmico de ordenamento turístico harmonioso.

\section{Subsistema 2: infraestrutura e superestrutura básica}

Como segunda camada do denominado Sistema Flexível de Turismo, tem-se o que se conhece por subsistema das Infraestruturas e das Superestruturas Básicas.

Ainda antes de discorrer sobre cada uma delas, ressalta-se que existe, neste ponto da explanação do sistema em questão, o intento de uma pequena contribuição: o lançamento da utilização da expressão Superestrutura acompanhada da terminologia "básica".

Enquanto de um lado a utilização da expressão infraestrutura básica é corriqueira e já internalizada por toda a sociedade, de outro, a expressão superestrutura básica ainda não.

Especificamente no turismo, o termo superestrutura é utilizado por inúmeros autores, entre eles, Beni (1988; 1997), quando explica sua proposta sistêmica denominada SISTUR. A terminologia é também utilizada por Goeldner, Ritchie \& Mc'Intosh (2002) em seus estudos sistêmicos.

De todas as maneiras, um dos intentos de inovação neste trabalho é a não utilização da terminologia em sua forma isolada [apenas palavra superestrutura], mas atrelá-la à outra terminologia [no caso, básica], considerando que, a posteriori, surgirão em outra camada do sistema as terminologias infraestrutura e superestrutura, acompanhadas da terminologia "turística".

Assim, o Sistema Flexível de Turismo lidará em sua totalidade, tanto com infraestruturas e superestruturas básicas, como turísticas.

No que concerne à infraestrutura básica e em consonância com o proposto por Boullón (1985), entende-se que ela diz respeito a todo tipo de construção fundamentada no interesse de prover à sociedade uma mínima condição e qualidade de vida. Ainda, referido autor (1997) menciona que as infraestruturas representam os bens e os serviços que permitem o desenvolvimento das estruturas sociais e produtivas de um país, como já mencionado neste trabalho.

Nesse contexto é que se mencionam os serviços de pavimentação, de saneamento básico, iluminação, educação e saúde, não criados especificamente para a atividade turística, mas utilizados por ela. Não há como uma comunidade bem receber ao turista, quando da falta de condições estruturais básicas.

Urge ressaltar, entretanto, que embora possa existir participação do setor privado nas providências de infraestrutura de uma localidade, o mesmo é de responsabilidade da gestão pública de cada município.

Sobre a relação infraestrutura básica e turismo, Cruz (2006: 338) menciona que: 
A implementação de obras voltadas a aumentar a fluidez do território, bem como outras destinadas à melhoria de condições infraestruturais básicas dos lugares $[\ldots]$ correspondem a algumas das ações estratégias emanadas do Estado [...] no sentido de desenvolver o turismo no território nacional. Tornar o território atrativo para o capital privado é o objetivo precípuo dessas ações.

Não é errado afirmar, dessa maneira, que a infraestrutura de uma localidade muito tem a contribuir para o desenvolvimento da atividade turística, exercendo, inclusive, força de atratividade. De qualquer maneira, o desenvolvimento da atividade, que aos poucos passa a gerar um aumento de fluxo na localidade turística, deve ser suficientemente planejado, para que a expansão dos serviços e da infraestrutura possa, também, acontecer.

Trata-se de um desenvolvimento paralelo e necessário e, talvez, considerado um dos grandes problemas nos destinos turísticos nacionais.

Enquanto países europeus parecem antecipar a questão das infraestruturas e das superestruturas de destinos turísticos, graças à prática eficaz de planejamento, países como o Brasil sofrem com os problemas que afetam a atividade, ainda antes de definidas ações para seu controle.

O que acontece, talvez, conforme mencionado por Vera Rebollo (1994), é que muitas vezes o que há são modelos pautados em um crescimento turístico muito rápido, guiados por impulsos da demanda, sem que haja tempo de colocar em prática qualquer ação de planejamento, da mesma forma que considerar a capacidade de assimilação de toda a estrutura regional.

Compreendido o conceito de infraestrutura básica, lança-se mão da apresentação do conceito de superestrutura básica, neste momento representada pelos diversos órgãos, públicos ou privados, e que de alguma forma visam à gestão do município ou localidade em questão.

Da mesma maneira que caracterizado quando apresentado o conceito de infraestrutura básica, a superestrutura básica também não possui sua existência justificada na atividade turística, senão na preocupação de uma gestão eficiente e eficaz do(s) município(s).

Fazempartedoroldoselementoscaracterizados pela superestrutura básica: Prefeitura Municipal,
Associação Comercial, Secretarias de Saúde, Meio Ambiente, Educação, Câmara dos Vereadores, Fórum, Serviço de policiamento, etc.

Não é difícil perceber que a união dos elementos mencionados, componentes das superestruturas básicas, é que formata e regula uma dada localidade, organizando e hierarquizando a sociedade, impondo seus limites e demonstrando seus direitos dentro dos preceitos da legislação existente e pertinente.

Da mesma maneira que o turismo carece de um mínimo de estrutura básica para sua organização, a atividade também necessita de um sistema básico de gestão que seja minimamente organizado e efetivo.

Como elementos das superestruturas básicas, hierarquicamente mais elevados, evidenciam-se: as prefeituras dos municípios, responsáveis pela gestão dos mesmos e a Câmara dos Vereadores, onde são criadas e definidas as leis do município e fiscalizada a administração local.

Daí a necessidade da constante comunicação de ambas as esferas, que, se bem orquestradas, são capazes de prestar auxílio para as secretarias do âmbito da educação, de saúde, meio ambiente e comercial.

A trama das relações entre as duas esferas mencionadas e as subsequentes acaba, por consequência, gerando as infraestruturas básicas necessárias para a sobrevivência da população em geral, autóctones e visitantes.

São infraestruturas básicas, como já mencionado: a pavimentação, o saneamento e a iluminação, todos eles totalmente interdependentes, possibilitando a criação de escolas, hospitais e unidades básicas de saúde, assistidas diretamente por suas secretarias responsáveis, assim como pela própria "alta hierarquia" das superestruturas básicas.

O que deve ficar claro, entretanto, é que, embora exista uma proposta de subsistema das infraestruturas e superestruturas básicas considerado "ideal" e "natural", muitas vezes o funcionamento de referido subsistema é alterado graças às peculiaridades da localidade, o que pode ser necessário, mas, muitas vezes, prejudicial.

\section{Subsistema 3: infraestrutura e superestrutura turística}

Com a mesma base conceitual das Infraestruturas e Superestruturas básicas, 
Infraestruturas_e Superestruturas turísticas são aquelas que têm sua existência justificada no desenvolvimento da atividade turística, ou seja, existem pelo fato da ocorrência da atividade turística em uma dada localidade; existem para fomentarem a atividade turística e torná-la o mais sustentável possível.

Assim, entende-se por infraestrutura turística, dentro da proposta do Sistema Flexível de Turismo, toda e qualquer estrutura criada para propiciar uma melhor execução da atividade turística.

Importante mencionar que as infraestruturas turísticas não apenas atendem aquele turista advindo de outros polos, mas, muitas vezes, ao morador da localidade turística que esteja se dirigindo à outra região.

Fazem parte do rol das infraestruturas turísticas os portos, as marinas, as rodoviárias, as estações de trem e metrô, os espaços culturais e de eventos, etc.

Nessa perspectiva, merece uma pequena reflexão em torno do mencionado.

Boullón (1997) concede outra nomenclatura às infraestruturas turísticas neste momento apresentadas. No caso, a denominação utilizada por ele é a de "instalações", ou seja, aquelas construções existentes para facilitar a prática turística. Já Goeldner, Ritchie \& Mc’'Intosh (2002) denominam essas construções que facilitam a prática de turismo de "superestruturas", o que para Beni $(1988 ; 1997)$ possui outro significado.

Importante trazer o posicionamento de diversos autores, justamente na tentativa de permitir com que o leitor consiga compreender a linha de raciocínio de um dado manuscrito, de acordo com seus autores.

Entendido o conceito de infraestrutura turística é que se culmina no conceito de superestrutura turística, essa que o Sistema Flexível de Turismo consona com o proposto por Beni (1988; 1997). A superestrutura turística representa todo elemento do sistema cuja finalidade é a de normatizar, regular e gerir especificidades da atividade turística, sendo caracterizada pela união dos poderes privado, público e não governamental.

Uma das peças chave para o bom ordenamento da atividade turística é a coesão e a proatividade dos elementos componentes da superestrutura turística.
São elementos da superestrutura turística os Conselhos Municipais de Turismo, Secretarias de Turismo, Associações de Classe específicas, Organizações Não Governamentais, etc.

Evidencia-se, neste ponto, que as estruturas físicas criadas, sejam elas destinadas ao turismo ou não, somadas às instituições reguladoras, sejam elas especificamente voltadas ao turismo ou não, sobrepostas aos inúmeros elementos de ordem natural, física, cultural, econômica e tecnológica, geram base ideal para as articulações inerentes ao desenvolvimento da atividade turística.

Visando facilitar a compreensão do funcionamento do subsistema das infraestruturas e superestruturas turísticas, menciona-se, da mesma maneira, o fato de que ambos, turistas e comunidade autóctones, acessam e fazem parte do subsistema em questão.

No que concerne às superestruturas turísticas, tem-se como esferas máximas o Conselho Municipal de Turismo e a Secretaria de Turismo, altamente interdependentes, cujas funções respectivas configuram-se em trabalhar no planejamento participativo e na gestão da localidade turística; formular ações estratégicas e políticas para a promoção da atividade turística local.

Embora a relação de ambas as esferas seja bastante estreita, não se deve furtar o fato de que as mesmas também se relacionam com as esferas menores subsequentes e não menos importantes, caracterizadas pelas Associações de Classe e Organizações Não Governamentais, isso pelo fato de que, de praxe, todas elas contam com cadeiras junto ao Conselho Municipal de Turismo e participam ativamente no planejamento participativo das localidades.

A importância das Associações de Classe se dá ao fato de que são elas aquelas que organizam o funcionamento do empresariado e da prestação de serviço local, sendo suas ações devidamente chanceladas pelo Conselho e pela Secretaria, da mesma forma que pelas superestruturas turísticas às quais são subordinadas e influenciadas em âmbito regional, estadual, nacional e internacional.

Da mesma maneira, de forma transversal, ONG's são criadas para desenvolverem ações que, indiretamente, trazem resultados benéficos às localidades, ao turista e à sua comunidade. $\mathrm{O}$ foco de trabalho das ONG's geralmente varia de 
acordo com a vocação turística de cada localidade, respeitando os aspectos ambientais existentes e as peculiaridades de sua comunidade autóctone.

Nessa perspectiva, visualiza-se, dentro do cerne das Superestruturas Turísticas, uma ampla relação entre as instâncias superiores, que apenas conseguem desempenhar seu papel, graças à existência e à participação ativa das instâncias inferiores.

É essa complexa relação e atuação conjunta das superestruturas turísticas que propicia a construção das infraestruturas turísticas, representadas pelos já mencionados portos, aeroportos, estações rodoviárias e ferroviárias, linhas de metrô e espaço de eventos. Todas interconectadas, na intenção de propiciar uma mobilidade facilitada a seus usuários: turistas e locais.

Por mais que seja clara a relevância do papel desempenhado dentro do subsistema das Infraestruturas e das Superestruturas turísticas, não se deve desconsiderar a imprescindível relação que referido subsistema mantém com o subsistema das Infraestruturas e Superestruturas básicas, da mesma forma que seu subsistema subsequente, denominado subsistema do tradel Mercado turístico.

Assim é que se atinge o patamar responsável pelo processamento no Sistema Flexível do Turismo, caracterizado pelo que se entende por subsistema Trade Turístico ou Mercado Turístico.

\section{Subsistema 4: trade turístico ou mercado turístico}

Cerne do Sistema Flexível de Turismo, a camada representada pelo mercado turístico serve de espaço para alocar todos aqueles elementos que, unidos, são capazes de configurar um dado serviço/produto turístico.

Ainda que isolados pouco signifiquem à atividade, toda a discussão sistêmica desenvolvida neste estudo foi capaz de demonstrar que, quando unidos e interconectados, geram, por meio do processamento do sistema, a experiência de viagem, ápice do sistema, ao considerá-lo uma pirâmide de camadas sobrepostas.

Dentre os elementos componentes do mercado turístico, destacam-se:

Quadro 2: Elementos do Sistema Turístico e seu papel

\begin{tabular}{|c|c|}
\hline Elementos & Papel \\
\hline $\begin{array}{l}\text { Agências de Viagens } \\
\text { e Turismo das } \\
\text { localidades }\end{array}$ & $\begin{array}{l}\text { Muitas vezes responsáveis pela articulação destino turístico versus zonas } \\
\text { emissoras, atuando como intermediadora de serviços, embora também } \\
\text { atendam a clientela de forma direta. }\end{array}$ \\
\hline $\begin{array}{l}\text { Meios de } \\
\text { Hospedagem }\end{array}$ & $\begin{array}{l}\text { Representados pelos meios de hospedagem hoteleiros e extra-hoteleiros } \\
\text { [hotéis, pousadas, resorts, campings, albergues da juventude, etc.], cuja } \\
\text { finalidade é a de hospedar o turista durante sua estada na localidade visitada. }\end{array}$ \\
\hline $\begin{array}{l}\text { Serviços de } \\
\text { Alimentação e } \\
\text { Bebidas }\end{array}$ & $\begin{array}{l}\text { Caracterizados por todos aqueles bares e restaurantes que atendem a } \\
\text { clientela viajante e comunidade local, ofertando os mais variados serviços } \\
\text { de alimentação. Embora se saiba que sua existência independe da atividade } \\
\text { turística, não se pode furtar ao fato de que muito restaurante tem seu } \\
\text { funcionamento totalmente atrelado à atividade turística. }\end{array}$ \\
\hline $\begin{array}{l}\text { Serviços de } \\
\text { Transporte }\end{array}$ & $\begin{array}{l}\text { Responsáveis pela movimentação dos turistas no destino. Sabe-se que } \\
\text { muitos dos turistas não acessam ao destino com seu veículo próprio. } \\
\text { Assim, serviços de transfer/shutle service, bem como serviços de transporte } \\
\text { entre atrativos tornam-se necessários. Fazem parte do rol dos serviços de } \\
\text { transporte aquelas empresas que oferecem transporte fretado, assim como } \\
\text { serviços de locação. }\end{array}$ \\
\hline
\end{tabular}




\begin{tabular}{|l|l|}
\hline Atrativos turísticos & $\begin{array}{l}\text { Locais que são visitados por aqueles turistas que estão em visita à localidade. } \\
\text { No contexto dos atrativos turísticos, configuram-se aqueles denominados } \\
\text { naturais, totalmente relacionados à camada 01(um) do Sistema Flexível de } \\
\text { Turismo, da mesma forma que aqueles construídos para atender a uma } \\
\text { demanda existente de turista. }\end{array}$ \\
\hline Comércio turístico & $\begin{array}{l}\text { Caracterizado por lojas e empresas especializadas na venda de produtos e } \\
\text { artefatos de caráter turístico, muitas vezes caracterizado pela cultura local, } \\
\text { por meio de sua mão de obra. Não deixa de representar uma forma de } \\
\text { valorização do patrimônio local e inserção da comunidade autóctone no } \\
\text { processo do turismo. }\end{array}$ \\
\hline Guia de Turismo & $\begin{array}{l}\text { Profissional formado para atuar com a prestação de serviços de informação } \\
\text { e guiamento aos visitantes de dada localidade. Embora nem todos os } \\
\text { atrativos careçam do acompanhamento de um guia de turismo, é esse o } \\
\text { profissional responsável por oferecer todo o suporte necessário ao viajante, } \\
\text { durante a execução de suas visitas. }\end{array}$ \\
\hline
\end{tabular}

Fonte: Os autores (2016).

Por fim, o Sistema Flexível de Turismo, como inovação, propõe que, somado a esses elementos do mercado turístico, esteja um elemento neutro, vazio, ou seja, uma espécie de "gaveta vazia", pronta para conceder espaço a um dado elemento chave, sempre que necessário. Trata-se do elemento "volante" do Sistema Flexível de Turismo.

No caso, dado o desenvolvimento de um aprofundado estudo sobre a realidade da atividade turística e sua condição de modernidade (TRIGO, 1998), (MOLINA, 2004), (SANTOS, 2008); (CACHO \& AZEVEDO, 2010), percebeu-se que algumas condições ambientais, geralmente apropriadas pela atividade turística e que são parte da camada 01 (um) do Sistema em questão, impreterivelmente assumem papel de um dos elementos do mercado turístico, camada 04 (quatro) do sistema, para que o processo interno do sistema possa realmente ser executado. Um dos exemplos trazidos em pauta é a força ambiental tecnológica.

Sabe-se que o mercado turístico, na "atualidade", dificilmente desenvolve qualquer atividade de reserva e controle sem a utilização da ferramenta tecnológica, já que toda ação é, obrigatoriamente, informatizada. Assim, não há como considerar a tecnologia apenas uma força ambiental do sistema, senão ferramenta essencial para o processo.

Nessa perspectiva, de maneira flexível, ela se desloca da camada base do sistema "Aspectos Ambientais Apropriados", inserindo-se junto dos demais elementos que compõem a camada do Trade/Mercado Turístico que, ao se comunicarem, gerarão o output ou experiência turística.
Da mesma maneira, em localidades cujo apelo natural e ecológico é muito latente, pode-se dizer que, por conta da própria fragilidade do sistema, a questão natural da camada base do sistema "Aspectos Ambientais Apropriados" pode também se deslocar para a camada cerne do sistema "Tradel Mercado Turístico", personificando-se por meio de instituições específicas, de maneira com que, por meio da união com os demais elementos do mercado, seja formatado um produto/serviço considerado ideal e que respeite a condição natural da localidade.

É por meio da geração do output do sistema que haverá o processo de retroalimentação e regulação do mesmo.

Visualiza-se, entretanto, a íntima relação da atividade turística com o meio ambiente. Não que demais elementos componentes do sistema turístico não sejam relevantes, mas é o meio ambiente aquele responsável por oferecer a matéria-prima original, imprescindível para o andamento da atividade.

Apresentadas todas as camadas ou compartimentos do Sistema Flexível do Turismo, basta dizer que o elemento humano, ou turista, ao inserir-se no Sistema, acaba por representar a energia, que somada aos aspectos ambientais apropriados e demais elementos dos subsistemas componentes do sistema, possibilitará todo seu funcionamento e produção.

$\mathrm{O}$ indivíduo assume, neste caso, tanto condição de elemento externo do sistema, como elemento interno, representando seu input. 
É a sobreposição das camadas mencionadas, suas forças e elementos, que se atinge a configuração da atividade turística que se conhece.

Importante papel desenvolvem as Instituições reguladoras básicas e turísticas, no intento de organizarem e planejarem uma atividade que seja, no mínimo, sustentada.

Assim, não diferentemente dos demais subsistemas, turistas e comunidade autóctone participam e acessam o subsistema do Trade/ Mercado turístico, permitindo seu movimento e funcionamento.

Dada a peculiaridade da localidade em questão, um de seus principais elementos é caracterizado por aquele denominado "volante", "flexível" e que ditará a forma de funcionamento do subsistema.

A partir das proposições do elemento volante é que as agências de turismo poderão, por exemplo, na tentativa de prestar o serviço mais adequado à sua clientela, contatar os serviços de meios de hospedagem para reservas de unidade habitacionais; reservar os serviços de transporte, de maneira a propiciar o deslocamento do turista intra-destino; contatar os serviços de atrativo turístico, com reserva e aquisição de vouchers de acesso e contratar os serviços de guiamento turístico para atuação intra-atrativos.

Da mesma maneira, a característica da localidade norteará a tipicidade oferecida pelos serviços de alimentação e bebidas, bem como nos artefatos vendidos nas lojas de souvenires.

Embora seja esta a sistemática "ideal" de funcionamento do subsistema do Trade/Mercado turístico adotada, inclusive, por alguns destinos nacionais e internacionais, sabe-se, porém, que a forma de organização de alguns destinos permite com que o turista, por si, acesse os inúmeros elementos do subsistema, de forma direta, o que pelo lado do consumidor pode ser considerado favorável, dada a condição do autosserviço, mas pelo lado da gestão, incoerente, dada a geração de dificuldade no controle da atividade.

Sendo este o último subsistema do Sistema Flexível de Turismo, pode-se afirmar que o subsistema do Trade/Mercado resulta da sobreposição e da interconexão de todos os outros subsistemas anteriores, sendo ele o responsável por personificar a experiência do viajante.
Assim, enfatiza-se, neste ponto, mais uma vez, o papel do turista, que, embora relevante e mencionado por inúmeros dos estudiosos apresentados, nem sempre tenha sido inserido em suas modelagens.

O Sistema Flexível de Turismo considera o turista como aquele elemento externo que, ao inserir-se no sistema, traz energia e serve de combustível para todas suas interconexões, responsáveis por gerar a experiência, consumida por ele mesmo.

\section{Metodologia}

Metodologicamente, pode-se afirmar que o estudo em questão possui caráter qualitativo, utilizando-se da pesquisa bibliográfica para levantamento de base teórica para o andamento do mesmo. A pesquisa bibliográfica correspondeu às obras relacionadas ao turismo, em especial, à área de planejamento e SISTURSistema Turístico; geografia; espaço e relação homem e natureza; tecnologia e turismo, bem como questões relacionadas ao meio ambiente e peculiaridades.

Na tentativa de levantar material bibliográfico suficiente para as leituras relacionadas ao tema proposto, o estudo bibliográfico caracterizouse por um levantamento de Estado da Arte, desenvolvido nos anos de 2014, 2015 e 2016, sistematizado, com busca de materiais em periódicos nacionais e internacionais e que se relacionavam às terminologias: Teoria Geral dos Sistemas e Turismo; Teoria dos Sistemas e Turismo; Teoria Geral dos Sistemas e Meio Ambiente; Teoria dos Sistemas e Meio Ambiente. Toda a busca foi feita nas línguas portuguesa, inglesa e espanhola.

Da mesma forma, priorizou-se acessar aos materiais que apresentavam a Teoria Geral dos Sistemas como base de análise para a atividade turística.

Dessa feita, apontam-se as obras de Ludwig von Bertallanfy (1967) e de Fritjof Capra (1996) como aquelas que permeiam a compreensão sistêmica para o turismo e que contribuíram para a criação de um modelo de análise atualizado, o que foi devidamente auxiliado por aquelas produções, cujos focos eram, especificamente, o turismo: (CUERVO, 1967); (LEIPER, 1979); 
(SESSA, 1985); (BOULLÓN, 1985); (GETZ, 1986); (ACERENZA, 1986; 1994); (BENI, 1988;1997), investigadores do assunto de grande relevância, profundamente estudados, e outros investigadores contemporâneos (SANTOS, 2007); (BAGGIO; SCOTT \& COOPER, 2010); (VERA REBOLLO; LÓPEZ PALOMEQUE; MARCHENA \& ANTÓN CLAVÉ, 2011); (PANOSSO NETTO, 2011); (VÁZQUEZ RAMÍREZ; OSÓRIO GARCÍA; ARELLANO HERNÁNDEZ; \& TORRES NAFARRATE,2013).

Não obstante, o estudo, ainda, caracterizou-se por uma fase de campo (empírica) desenvolvida no município de Bonito-MS, destino consolidado no Brasil. Trata-se da etapa responsável por validar o modelo de análise proposto neste artigo, que é, inclusive, disponibilizado em outro trabalho científico com tal objetivo.

De todas as maneiras, ressalta-se que o trabalho de validação do modelo proposto ocorrido no município de Bonito-MS contou com aplicação de entrevistas a atores do turismo do município. O quantitativo dos atores pesquisados, entretanto, não se pautou em nenhum cálculo amostral previamente definido, justamente pelo fato de que o estudo de campo se caracterizou por uma abordagem qualitativa, onde se prezou pela profundidade e não quantidade. Da mesma forma, com base nas propostas de Getz (1986), buscouse, de antemão, definir todos aqueles possíveis elementos componentes do sistema estudado para fins de abordagem e entrevistas.

Basicamente, fizeram parte do rol dos entrevistados:

- Um atrativo de cada um dos 06 segmentos existentes no município, tendo sido entrevistados seus gestores, um funcionário, um guia de turismo e um turista [em cada um deles]. Apenas o atrativo de Mergulho é que teve somente seu gestor entrevistado.

Com relação às entrevistas aplicadas aos gestores dos empreendimentos de Hospedagem [um representante para cada classe hoteleirapequeno, médio e grande porte]; Alimentação e Bebidas [01 restaurante da zona turística e outro da zona não turística]; Agenciamento de Viagens [01 representante de uma agência receptiva]; Serviço de Transporte [01 representante de uma transportadora] e Comérciolocal [01 representante de uma loja local]; importante ressaltar que os mesmos foram escolhidos de acordo com anseio do pesquisador e disponibilidade.

Órgãos reguladores Ambientais, Secretaria do Meio Ambiente (SEMA) e Instituto do Meio Ambiente do Estado (IMASUL) e do Turismo, Secretaria de Turismo (SECTUR) e Conselho Municipal do Turismo (COMTUR), também foram entrevistados [01 representante de cada].

Da mesma forma, optou-se por entrevistar representantes das Associações do Município: Associação dos Atrativos turísticos (ATRATUR), Associação dos Guias de Turismo (AGTB), Associação dos Bares e Restaurantes (ABRASEL), Associação das Agências de Turismo (ABAETUR), Associação Bonitense de Hotelaria (ABH) e Associação Comercial (ACEB) [01 representante de cada].

Por fim, duas Organizações Não Governamentais (ONGS) [01 representante de cada], além de um residente, também foram entrevistados.

Todas as entrevistas compuseram-se por um núcleo comum de questões que buscavam levantar o entendimento dos entrevistados acerca de um sistema turístico, da mesma maneira que levantar suas opiniões sobre o grau de importância dos elementos componentes do sistema turístico do destino e as relações existentes entre os referidos elementos. Ainda, um núcleo de questões específicas para cada grupo de entrevistados serviu para que se propiciasse aos pesquisadores maior conhecimento sobre suas funções e atividades.

Após análise das entrevistas, a partir de alguns preceitos propostos por Bardin (1971), podese compreender o funcionamento do sistema proposto no município em questão.

Dentre os aspectos mais relevantes, evidenciou-se que o apelo ambiental do destino e a necessidade da tecnologia nos processos de reserva, emissão de vouchers e controle de capacidade de carga dos atrativos assumem força suficiente para se personificarem em elementos volantes do Sistema Flexível de Turismo, os quais se deslocam para o subsistema trade/mercado, no sentido de gerarem a experiência turística. O estudo, da mesma maneira, no intento de relacionar o sistema proposto com o ambiente, demonstrou que o destino ainda não atende de forma integral os preceitos da sustentabilidade, embora se venda e seja reconhecido como tal. 


\section{Considerações finais}

A construção de um trabalho de caráter metodológico, composto pela proposição de um modelo de análise do turismo, atualizado, gerado a partir da compreensão e da reflexão acerca dos principais postulados dos autores que utilizaram a Teoria Geral dos Sistemas para compreender o Turismo no decorrer histórico surgiu, uma vez que os resultados das análises de suas propostas puderam ser confrontados com as peculiaridades da atividade turística da "atualidade", século XXI.

Tal intento surgiu pelo simples interesse de demonstrar que todo o conhecimento existente de referida teoria para a análise da área talvez já não fosse suficiente para compreender a dinâmica e complexa realidade da atividade, nos tempos atuais, atribuída ao fato de que as propostas existentes até o momento não contemplaram, em suas modelagens, a perspectiva tecnológica; da mesma maneira que apenas apresentaram as questões ambientais como ambiente influenciador e influenciado pelo sistema.

Acaracterística comum inerente aos postulados existentes compunha-se de um panorama rígido não condizente à realidade turística, por si flexível. Daí a busca por propiciar não apenas um avanço nas discussões, mas desenvolver a proposta de um modelo atualizado, passível de aplicação em outras realidades, capaz de analisar de forma sistêmica destinos turísticos, respeitando suas condições de flexibilidade.

Dessa feita, não é incorreto afirmar que as análises sistêmicas na perspectiva da flexibilidade da atividade turística parecem não ter acompanhado a rapidez do desenvolvimento da atividade, que em pouco tempo passou a contar com novos elementos para sua formatação. A própria afirmação de López Palomeque (1999: 24) de que "a evolução do turismo nas últimas décadas $[\ldots]$ tem mostrado características específicas que se interpretam como indícios e evidências de uma mudança no turismo, de uma nova fase na história deste importante fenômeno social" acaba por demonstrar a necessidade do desenvolvimento de estudos contínuos capazes de melhor compreenderem o dinamismo da atividade.

Assim, como inovação deste estudo é que se apresentou o Modelo Flexível de Turismo, criado com base em todo o arcabouço teórico levantado no decorrer do desenvolvimento do estado da arte do estudo em questão.

Após a proposta do novo modelo de análise e considerando os objetivos principais dos estudos científicos, que ponderam o compartilhamento do conhecimento produzido, no intento de trazer algum benefício à sociedade, considerouse prioridade da pesquisa aplicar o modelo apresentado neste manuscrito em um destino turístico nacional. A intencionalidade de aplicação do modelo em uma dada realidade serviu de possibilidade de validação da metodologia em questão, cujos resultados foram altamente satisfatórios.

A partir do exposto e da pesquisa desenvolvida, não restou dúvida de que a Teoria Geral dos Sistemas é pertinente para estudar realidades turísticas, dado seu caráter generalista e holístico.

Por mais que uma de suas características seja a generalidade, tem-se que a Teoria Geral dos Sistemas representa um método de análise capaz de compreender a amplitude e a perspectiva compósita da atividade turística, de uma única vez, propiciando um olhar holístico e complexo.

Trata-se de uma teoria bem recebida pelo turismo, graças à sua afinidade com a geografia que já a utilizava para estudar os espaços.

Não criada especificamente para o turismo, como apresentado, mas apropriada por ele, já pelos idos da década de 80 percebia-se que a Teoria Geral dos Sistemas era indicada para estudos das Ciências Sociais, da mesma forma que para as Ciências da Vida, dado seu caráter holístico, algo discutido por Capra (1982) em sua obra "Ponto de Mutação".

A partir do momento em que a Teoria Geral dos Sistemas passou a ser assimilada pelos campos das Ciências Sociais, rapidamente o turismo passou a considerá-la, graças aos estudos, já sistêmicos, realizados pela área da Geografia.

Por essa razão, são inúmeros os investigadores sistêmicos referenciados nos estudos turísticos, sejam eles do ramo da Biologia, Geografia, outras áreas ou do próprio campo do Turismo.

Especificamente, grande destaque recebe o biólogo Bertalanffy, criador da teoria (1967); Capra, também ambientalista (1982; 1995; 1996; 2002); o geógrafo Christofoletti (1977; 
1999); além de investigadores de diversas áreas que dedicaram suas pesquisas à aplicabilidade da Teoria Geral dos Sistemas para a análise do turismo, como Cuervo (1967); Leiper (1975); Sessa (1985); Boullón (1985); Acerenza (1986; 1994) e o brasileiro Beni (1988; 1997).

Não se desconsidera, neste estudo, entretanto, a existência de outros investigadores que também estudaram a Teoria Geral dos Sistemas ou a utilizaram para estudar a área do turismo neste estudo já apresentados.

O que se percebeu durante a sistematização do estudo foi um claro aperfeiçoamento e aprofundamento da teoria para a análise do turismo no transcorrer da história; estudos esses que apresentam sua validade e sua contribuição, em especial, no período de suas publicações, mas que quando analisados a partir dos preceitos da pós-modernidade, apresentaram lacunas, no que tangia aos aspectos tecnológicos [parte do meio ambiente], além de caracterizados por um padrão rígido e não flexível, ou seja, uma antítese ao que se tem por turismo na atualidade.

Não caracterizados os postulados estudados por grandes inovações, mas por pequenas contribuições quando comparados à proposta anterior, foi fácil perceber que o avanço dos estudos sistêmicos para o turismo apenas existiu graças ao somatório de todas as suas produções. Uma serviu de alicerce para a outra, como se fosse um "degrau de escada". Para cada proposta, uma nova contribuição, um pequeno avanço.

Ao tomar em consideração todas as produções analisadas, foram evidenciados aspectos comuns e aspectos distintos.

De um lado, foi visível perceber que as propostas de análise sistêmica da atividade turística visavam implementar ações de planejamento eficientes e eficazes, condição não necessariamente idealizada neste estudo, que apenas se utilizou da Teoria Geral dos Sistemas como um método viável de análise do turismo.

De outro lado, porém, evidenciaram-se propostas que apenas propunham modelos de análise sistêmica, sem qualquer demonstração de sua aplicabilidade, revestidos de discussão meramente teórica. Houve as propostas que apresentaram modelos sistêmicos macro, da mesma maneira que outras apresentaram modelos dentro da perspectiva micro.
A grande contribuição do estudo, porém, foi perceber da necessidade de algum tipo de produção que demonstrasse a seu leitor um modelo passível de aplicabilidade, o que não foi localizado no levantamento do "Estado da Arte".

Os materiais estudados ou apresentavam propostas de modelo sem sua aplicabilidade ou desenvolviam análises sistêmicas de realidades, sem a demonstração de sua modelagem sistêmica.

Este, talvez, tenha sido o maior incentivo para a construção do presente trabalho em estudar uma teoria; adequá-la à realidade; propondo um modelo sistêmico de análise flexível o suficiente para se adaptar à diversas outras realidades.

Foi estudando a realidade de um destino nacional [como estudo piloto] que se concluiu, da mesma maneira, que não havia possibilidade de indissociar a relação turismo e meio ambiente nos processos de análise sistêmica, já que o sistemismo, no turismo, considera a complexidade das inúmeras relações existentes entre os elementos componentes da atividade e o meio ambiente: natureza, patrimôniocultural, aspectos econômicos, tecnologia e sociedade. Tratam-se daqueles primeiros elementos apropriados e que servem de base para o desenvolvimento e para a construção do sistema [sobreposição de suas camadas].

Considerando que inevitavelmente a atividade turística gera impactos, conclui-se que as questões de ordem ambiental dizem respeito tanto àquelas comunidades das localidades receptoras, como daqueles que, por razões distintas, buscam uma prática turística positiva.

Daía necessidade de refletir a prática sustentada da atividade, no intento de propiciar ciclos contínuos, com entrada (input), produção, saída (output) e retroalimentação equilibrados. Trata-se do objetivo de qualquer sistema: funcionamento continuado e equilibrado.

Se o que se enseja é uma prática sustentada da atividade, importante se faz a utilização de meios capazes de propiciar uma análise totalitária das realidades turísticas. A Teoria Geral dos Sistemas, por meio do Sistema Flexível do Turismo, corresponde a uma das ferramentas que possibilitam o atingimento de referido fim, ao mesmo tempo em que considera as diversas variáveis da atividade em seu âmbito flexível.

Por essa razão é que se considera o trabalho desenvolvido relevante. Não apenas por ter 
cumprido com o atendimento a seus objetivos e pressupostos de pesquisa, trazendo inovação e contribuição científica, mas, da mesma maneira, por servir de meio para o andamento de outros estudos.

\section{Referências}

ACERENZA, M.A. (1994). Administração do Turismo. Bauru: Universidade do Sagrado Coração. Trillas.

(1996). Administración del Turismo. Mexico:

BARDIN, L. (1971). Análise de conteúdo. São Paulo: Edições 70.

BEJARANO MARTINEZ, E. S. (2009).Una geografía del turismo: para la comprensión de la territorialización turística. 12 Encuentro de geográfos de América Latina, Montevideo, Uruguai.

BENI, M.C. (1998). Sistema de Turismo: construção de um modelo teórico- referencial para aplicação na pesquisa em turismo. Tese de Doutorado, Ciências da Comunicação, Universidade de São Paulo, São Paulo, SP. Senac.

(2006) Análise Estrutural do Turismo. São Paulo:

BERTALANFFY, L.W. (2012). Teoria Geral dos Sistemas. 6 ed. Petrópolis: Vozes..

BOUlLÓN, R.C. (1985) .Planificción Del Espacio Turístico. México, Trillas..

(1997). Planificción Del Espacio Turístico. 3 ed. México, Trillas..

BUTLER, R.W. (1991). Tourism, Environment, and Sustainable Development. Environmental Conservation.

CACHO, A.N.B.; AZEVEDO, F.F. (2010). O Turismo no contexto da sociedade informacional. Revista Brasileira de Pesquisa em Turismo. Vol.4, 2, p. 31-48.

CAPRA, F. (1982). Ponto de Mutação. São Paulo: Cultrix.

(1995). A Teia da Vida. São Paulo: Cultrix.

(1996). A Teia da Vida. São Paulo: Cultrix.

(2002). Conexões Ocultas: ciência para uma vida sustentável. São Paulo: Cultrix.

CHRISTOFOLETTI, A. (1997). Análise dos Sistemas em Geografia. São Paulo: HUCITEC.
(1999). Modelagens de Sistemas Ambientais. São Paulo: Blucher.

CRUZ, C.A.R. de. (2006). Planejamento governamental do turismo: convergências e contradições na produção do espaço. América Latina: cidade, campo e turismo. Amalia Inés Geraiges de Lemos, Mónica Arroyo, María Laura Silveira. CLACSO, Consejo Latinoamericano de Ciencias Sociales, San Pablo.

CUERVO, R. (1967). Estudios y Desarollo de las Zonas Turísticas. Cuadernos Técnicos de Turismo. Instituto Mexicano de Ivestigaciones Turisticas. México.

(1967). Tourism as a Medium of Human Comunication. Departamento de Turismo do Governo Mexicano. México.

DREDGE D. (1999). Destination Place Planning and Design. Annals of Tourism Research. Vol.16, 4, p. 772-791.

FIORILLO, C.A.P. (2003). Curso de Direito Ambiental Brasileiro. São Paulo: Saraiva.

GETZ, D. (1986). Models in Tourism Planning: towards integration of theory and practice. Tourism Management.

(1986). The Tourism System: an introductory text. Annals of Tourism Research: 143-146.

GOELDNER, C.R. RITCHIE, J. R. B \& Mc' INTOSH. R. W. (2002). Turismo Princípios, Práticas e Filosofias. 8 ed. Bookman.

HALL, C.M.; PAGE, S. (2010). The contributions of Neil Leiper to Tourism Studies. Current Issues in Tourism. Vol.13, 4, p. 299-309.

HALL, C.M. (2001). Planejamento Turístico: políticas, processos e relacionamentos. São Paulo: Contexto.

INSKEEP, B. (1991). Tourism Planning: an integrated and sustainable development approach. New York, Van Nostrand Reinhold.

LAGO, R.; CANCELLER, E.L.P.L. (2005). Agência de Viagens: desafios de um mercado em reestruturação. Turismo - Visão e Ação. vol. 7,3, p.495 - 502.

LEIPER, N. (1979). The Framework of Tourism: Towards a Definition of Tourism, Tourist and the Tourist Industry. Annals of Tourism research. Oct/ Dec.

LÓPEZ PALOMEQUE, F. (1999). Política turística y territorio en el escenario de cambio turístico. Boletín de la A.G.E, 28, p. 23-38.

MOLINA, S. (2004). O Pós-Turismo. Tradução Roberto Sperling. São Paulo: Aleph.

MOWFORTH, M.; MUNT, I. (2003). Tourism and Sustainability: development and new Tourism in the third World. New York: Routledge.

PANOSSO NETTO, A. (2011). Filosofia do Turismo: teoria e epistemologia. 2 ed. São Paulo: Aleph. 
RUSCHMANN, D.V. de. M. (2003). Turismo e Planejamento Sustentável: a proteção do meio ambiente. 7 ed. Campinas, Papirus.

SANTOS, G.E.O. (2007). Modelos Teóricos Aplicados ao Turismo. Estudios y Perspectivas en Turismo, vol.16, p. $96-110$.

SANTOS, M. (1984). Espaço e Método. São Paulo: Nobel.

(2008). Técnica, espaço, tempo: globalização e meio técnico-científico-informacional. 5 ed. São Paulo: Edusp.

SESSA, A.(1985). La scienza dei sistema per $i$ piani regionali di sviluppo turistico. La scienza dei sistemi per lo sviluppo del turismo, p. 53-107.

(1988). The Sicence of Systems for Tourism Development. Annals of Tourism Research. Vol.15p. 219-235.

TRIGO, L.G.G. (1998). A Sociedade Pós-Industrial e o profissional do turismo. Campinas: Papirus.

VÁZQUEZ RAMIRES, D.R.; OSÓRIO GARCIA, M; ARELLANO HERNANDEZ, A.; TORRES NAFARRATE, J. (2013). El turismo desde el pensamiento sistémico. Investigaciones Turísticas. Vol.5, p. 1-28.
VERA REBOLLO, J.F. (1992). La Dimensión Ambiental de la Planificación Turística: una nueva cultura para el consumo turístico. Papers de Turismo. Vol.10.

(1994). El modelo Turístico del Mediterráneo Español: agotamiento y estrategias de reestruturación. Papers de Turismo. p.14-15.

VERA REBOLLO, J.F.; LÓPEZ PALOMEQUE, F.; MARCHENA, M.J.; ANTON CLAVÉ. (2011). A Análise territorial do turismo e planejamento de destinos turísticos. Valencia: Tirant lo Blanch.

WILLIAMS, S. (1998). Tourism Geography .London: Routledge.

\section{Contribuições de cada autor}

Guilherme Garcia Velasquez: Referencial Bibliográfico, Confecção do material de coleta de dados, Aplicação do material de coleta de dados, Escrita dos Resultados.

Josildete Pereira Oliveira: Referencial Bibliográfico, Confecção do material de coleta de dados, Revisão do Estudo. 